\title{
Research on the Training Effect of New Farmers in Beijing
}

\author{
Yaming Zheng ${ }^{1,2, a}$, Changshou Luo ${ }^{1,2, b^{*}}$, Chengzhong Cao ${ }^{1,2, c}$, \\ Qingfeng Wei ${ }^{1,2, d}$, Jun $\mathrm{Yu}^{1,2, \mathrm{e}}$ \\ ${ }^{1}$ Institute of Agricultural Information and Economics. Beijing Academy of Agriculture and Forestry \\ Sciences, Beijing, China \\ Beijing Research Center of Engineering Technology on Rural Distance Information Service, Beijing, \\ China \\ azhengym@agri.ac.cn, bluocs@agri.ac.cn, ccaocz@agri.ac.cn, dweiqf@agri.ac.cn, eyuj@agri.ac.cn \\ ${ }^{*}$ Corresponding author
}

Key words: New farmers, Training, Effect

\begin{abstract}
With the development of economy and science technology, the level of agricultural modernization has developed higher and higher. And it is necessary to train new farmers and high-quality professional farmers. This paper introduces how to carry out the training classes for new farmers firstly, and then discusses the effect of training, finally puts forward advices from three aspects about how to improve the training effect of new farmers.
\end{abstract}

\section{Introduction}

In recent years, the level of agricultural modernization has developed quickly, and farmers' knowledge and skills cannot adapt to new needs of rural industry. Thus, it is necessary to train new farmers and high-quality professional farmers to keep up with this change [1]. New farmers' training is the key to solve the problem of "Three Rural Issues", which can improve the new farmers' technical abilities and comprehensive qualities. Meanwhile, it is meaningful to help farmers to increase income and promote agricultural efficiency [2-3]. Through the practice of training for new farmers and investigation the training effect in Beijing, this paper puts forward advices on how to improve training effects of new farmers, which could be used as reference for the training of new farmers.

\section{Organization of the Training}

In 2016, the first and second phases of 'The advanced training classes on agricultural e-commerce and agricultural water saving technology in Beijing' were organized by the project team. This part focuses on the whole processes and details of the training.

2.1 The Preliminary Survey and the Training Plan Development. Before the formal trainings, we received a large number of training wishes and ideas from the new farmers in several ways in Beijing. We went to Daxing, Miyun, Tongzhou and other districts in the suburbs of Beijing to carry out a number of field researches, and also used these methods such as questionnaires, telephone interviews, etc. Then, targeted implementation plan with the basic characteristics of each district was developed.

2.2 Organization and Management of the Trainings. The leading group was set up to coordinate, supervise, check the trainings and solve the urgent problems. The work team was formed and divided into the planning group, materials group and meeting affairs group, which responsible for the seminar specific. The teaching expert team was established to direct at the training needs and ensure the professional technical resources. Then, new farmers as students were called in through QQ, WeChat and other new media platforms.

2.3 Carrying Out the Training Work. The trainings were carried out by lectures and field observation, which could improve the students' interests and ensure the training effects. 
Management ledger was established. The work team made advance notices of the course and did a good job of attendances and training records of each course, including the specific training time, place, experts, content and attendance of students, etc. The WeChat groups were established for further communicating, which could facilitate learning and communication. A variety of learning materials were provided and special panels were made to provide technical support for students, which could improve the learning efficiency. The expert assistance and guidance were provided through the 12396 Beijing agricultural hotline multi-channel services, which could make sure the technical guidance after the training.

\section{Training Effect Analysis}

The study of training effect was carried out by investigating questionnaires which involved 115 participants in the study. A total of 106 valid questionnaires were collected. In the satisfaction evaluation on the training, $62.2 \%$ were very satisfied, $37.8 \%$ satisfied, and there was no one unsatisfied with the training. Actually, this type of training basically meet the real needs of the new farmers. In the evaluation of the level of experts' teaching, $64.4 \%$ students are very satisfied, equal to the percent of the teaching contents, and $35.6 \%$ indicated that a wealth of practical experience for students. The satisfaction evaluation on the training organization, $86.7 \%$ students were satisfied, and the remaining $13.3 \%$ felt satisfied. Also, there was no unsatisfied questionnaire (Fig. 1).

After the training, 94\% of the participants considered that the training was in line with expectations and $6 \%$ general; $92 \%$ of the participants considered training could impact on the breeding structure, in the evaluation of the training effect. $23 \%$ considered that the training of science and technology was very useful for raising the income. And $90 \%$ of the participants after the training were also very willing to participate in the training, and $97 \%$ of people intended to adopt agricultural water-saving technology, and were willing to introduce it to others.

A further survey, on the training of agricultural water-saving technical, found that $48.9 \%$ concerned with agricultural water conservation policies, $77.8 \%$ wanted to obtain water-saving facilities, $48.9 \%$ and $51.1 \%$ of students concerned with water-saving facilities maintenance, water-saving crop varieties, etc. (Fig. 2). After the investigation of further training of agricultural e-commerce, it was found that lessens on platform and technology, operation and promotion were $75.6 \%$ and $64.4 \%$ welcomed, respectively, and Micro-business and related policies accounted for $55.6 \%, 37.8 \%$ (Fig. 3). New farmers had high hopes for training, hoping to organize more such training.

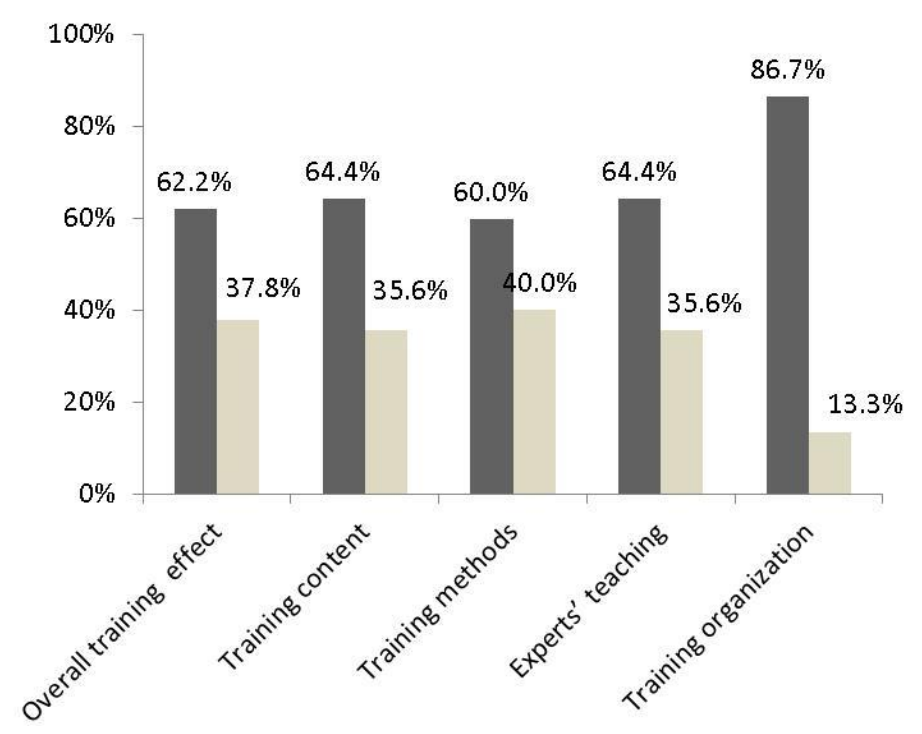

Fig.1 Satisfactions on training of the overall effect, content, methods, experts' teaching, organization and management 


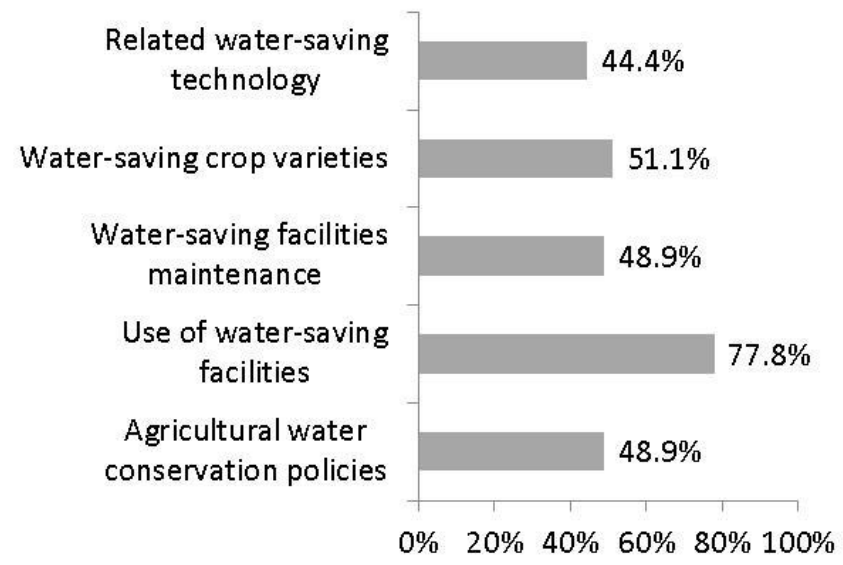

Fig.2 New farmers' demands for agricultural water-saving technology

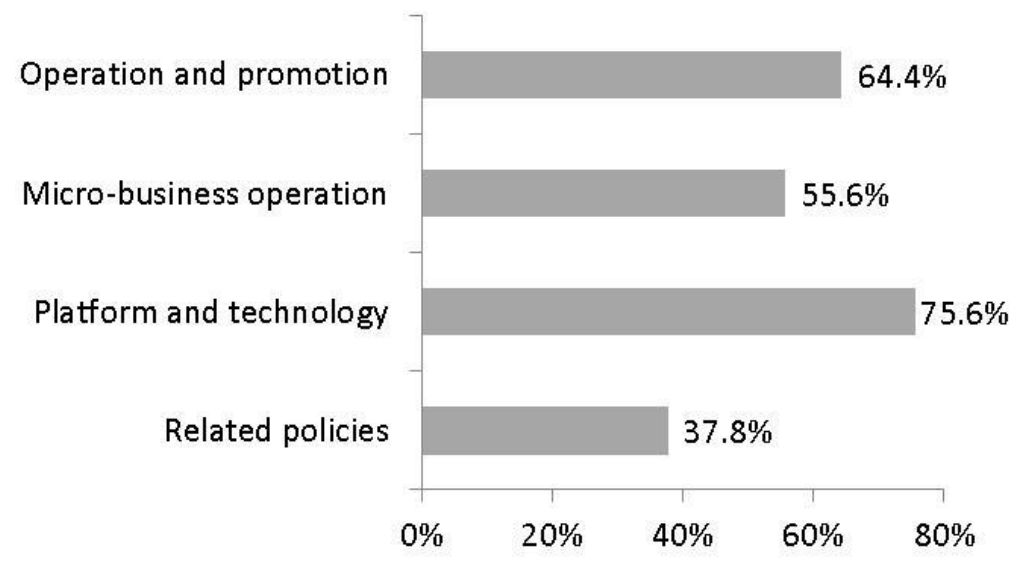

Fig.3 New farmers' demands for agricultural e-commerce

\section{Summary and Suggestion}

Science and technology training for new farmers is not only a systematic project, but also a complex and arduous cause, which needs attract the attention of the government and the whole society.

New farmers training project is needed to promote vigorously, as a wide coverage, multi-channel, multi modes of farmers training. Through increasing the training publicity, more farmers can easily access to the training information and take part in to improve their knowledge and technologies. Optimizing the distribution of training resources, can ensure that the limited training resources used efficiently, and the agriculture development promoted more effectively.

The survey of training needs should be increased. It is helpful to improve the pertinence in the training process, not only helping us understanding the teaching contents farmers need, but as a basis to select the appropriate mode of training, which help new farmers learn the knowledge and skills well and to achieve better training effect.

Rich training methods and technical guidance after the training need strengthen, which will be improved to arouse new farmers' motivation, in the future process of training. At the same time, agriculture investment, manufacturing, marketing, and so on, are needed to give appropriate support and follow-up. Consequently, the training will produce better comprehensive benefits.

\section{Acknowledgement}

This study was supported by the fund of Institute of Agricultural Information and Economics, BAAFS: A preliminary study on the visual retrieval technology of agricultural technology consultation knowledge(NO.2016XXS006), the young scientist fund of BAAFS: Research on 
agricultural scientific technical online counseling system based on the knowledge map (NO.QNJJ201534), the innovation fund of BAAFS: Agricultural water-saving technology training and counseling service demonstration project (NO.KJCX20151409), the fund for agriculture of Beijing municipal commission of rural affair: The application of APP and "zixuntong" products in the management and service of general agricultural technicians.

\section{References}

[1] Y. Wang, A few ways to Improve the Training effect of Agricultural Promotion school Farmers Training, Times Agricultural Machinery, Vo1.43, pp. 129-130, 2016.

[2] S. Y. Tan. The present situation and improvement of farmers' training. Modern Agricultural Science and Technology, Vo1.8, pp. 30-33, 2016.

[3] X. M. Fu and T. H. Zhuang, Training modes of new professional farmers and factors influencing training effect in Chengdu, Guizhou Agricultural Sciences, Vol 44, pp. 171-176, 2016. 